\title{
Implementation of Close Loop Speed Control with VVVF Control and Slip Regulation on LIM
}

\author{
Kunwar Aditya \\ M.Tech, Department of electrical engineering \\ IT BHU \\ Varanasi, India \\ kunwar.aditya.eee10@itbhu.ac.in
}

\author{
Albert Newwel \\ M.Tech, Department of electrical engineering \\ IT BHU \\ Varanasi, India \\ albert.newwel.eee10@itbhu.ac.in
}

\begin{abstract}
Open loop VVVF control has the disadvantage of low output torque when working at low frequency and poor speed precision at different load conditions. Various performanceimproving schemes have been proposed for the basic VVVF control by compensating slips occurring in the low frequency range and slips caused by changing loads and several papers have been published on the close loop speed control of rotary induction motor. In this paper a close loop speed control with VVVF control and slip regulation has been implemented for LIM based conveyor belt test Rig which compensates the disadvantages of traditional Volts/Hz control. SIMULINK results are presented to validate the effectiveness of the proposed scheme.
\end{abstract}

Keywords-Linear induction motor; close loop speed control; slip regulation; VVVF control

\section{INTRODUCTION}

The VVVF scalar control scheme has been used broadly in the industry due to the speed/torque control advantage in rotary induction motor based drives. However, in the traditional VVVF scalar control the percentage voltage drop across the stator resistance is more dominant compared to the voltage drop for the production of the main flux at low frequencies. In addition, the VVVF scalar control scheme provides open loop control, and therefore the system cannot maintain speed accuracy both at low frequency and high load operation. To overcome these drawbacks, VVVF scalar control with slip frequency regulation is being widely suggested [1, 2]. Recently, linear induction motors (LIM) are being adopted for certain applications due to their obvious advantages over rotary induction motors [3]. Practical applications of these motors to various linear drives are now numerous [4]. In this paper, VVVF control with slip frequency regulation has been implemented on a linear induction motor to demonstrate the effective closed loop control of linear speed. Simulation results have been obtained using MATLAB/SIMULINK.

\section{CONTROL STRATEGY}

Figure1 represents the block diagram of the control strategy $[2,5]$ which has three distinct parts: the v-f control, the stator resistance voltage compensation and the slip frequency compensation. A strategic block diagram of close loop speed control is shown in Figure 1. The actual speed of the secondary member $(\mathrm{Vr})$ is compared with its commanded value $\left(\mathrm{Vr}^{*}\right)$ and the error is processed through a PI controller and a limiter to obtain the slip-speed command, Vsl*. The limiter ensures that the slip speed command is within the maximum allowable slip speed of the LIM. The slip speed command is added to the speed of the secondary member to obtain the synchronous speed, $\mathrm{Vs}^{*}$ for generating a frequency command. The frequency command then generates a voltage command through a volts/Hz function generator. To compensate for the primary-member-resistance-voltage drop, a boost voltage is added to the generated voltage so that the desired rated flux and hence the corresponding thrust becomes available down to zero speed. Effect of boost voltage, however, becomes negligible at higher frequencies. Figure 2 portrays a typical SIMULINK model of linear induction motor in $\mathrm{d}-\mathrm{q}$ stationary reference frame. The parameters and specification of LIM based conveyor belt test rig used in the SIMULINK model are given in Table I.

TABLE I. PARAMETERS \& SPECIFICATIONS OF LIM

\begin{tabular}{|c|c|}
\hline Voltage(line-line) & $440 \mathrm{~V}$ \\
\hline Frequency & $50 \mathrm{~Hz}$ \\
\hline Number of poles $(\mathrm{P})$ & 8 \\
\hline Primary resistance $\left(\mathrm{R}_{1}\right)$ & $64 \Omega$ \\
\hline Primary leakage reactance $\left(\mathrm{X}_{1}\right)$ & $108.7 \Omega$ \\
\hline Magnetizing reactance $\left(\mathrm{X}_{\mathrm{m}}\right)$ & $76.15 \Omega$ \\
\hline Secondary resistance $\left(\mathrm{R}_{2}\right)$ & $1.7 \Omega$ \\
\hline Secondary reactance $\left(\mathrm{X}_{2}\right)$ & $72 \Omega$ \\
\hline Mass of copper belt $(\mathrm{M})$ & $1.99 \mathrm{Kg}$ \\
\hline Coefficient of friction $(\mathrm{b})$ & $0.028 \mathrm{~N}-\mathrm{sec} / \mathrm{Kg}$ \\
\hline Pole pitch & $.099 \mathrm{mts}$ \\
\hline
\end{tabular}

\section{SimULATION RESUlTS}

The simulation results for the following cases are presented and discussed:

- Case A: Effect of Step Change in Reference Speed at No Load

- Case B: Effect of Boost Voltage at Low Frequency

- Case C: Effect of Slip Regulation

- Case D: Performance under Load Variation 


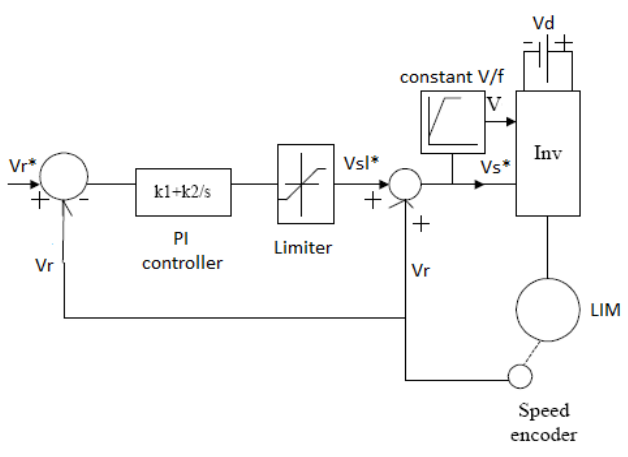

Fig. 1. Strategic block diagram of close loop speed control

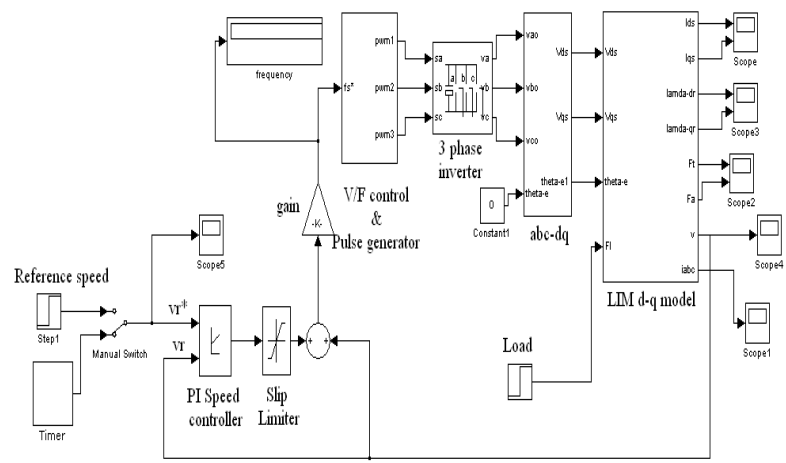

Fig. 2. SIMULINK model of close loop speed control with volts/Hz control and slip regulation

\section{A. Case A: Effect of Step Change in Reference Speed at No Load}

To validate the control strategy, at no load condition the frequency has been set to change in the SIMULINK model from $15 \mathrm{~Hz}$ to $50 \mathrm{~Hz}$ at a frequency-step of $5 \mathrm{~Hz}$ every $7 \mathrm{sec}$. The no load however includes the weight of the moving conveyor belt and the friction offered during motion. Figure 3 shows that the variation of actual linear speed closely follows the reference linear speed (with respect to simulation time) due to the change in frequency. The variation of the inverter output phase voltage with respect to the simulation time due to the change in frequency is shown in Figure 4. The results of Figures 3 and 4 have been arranged in tabular form in Table II to demonstrate the validation of the model.

TABLE II. VARIATION OF INVERTER OUTPUT PHASE VOLTAGE AND LINEAR SPEED W.R.T. REFERENCE SPEED

\begin{tabular}{|c|c|c|c|c|}
\hline $\begin{array}{c}\text { Ref. } \\
\text { speed } \\
\text { (m/s) }\end{array}$ & $\begin{array}{c}\text { Actual } \\
\text { speed } \\
\text { (m/s) }\end{array}$ & $\begin{array}{c}\text { Frequency } \\
\mathbf{( H z )}\end{array}$ & $\begin{array}{c}\text { Inverter output } \\
\text { phase voltage } \\
\text { (volts) }\end{array}$ & $\begin{array}{c}\text { Volts-to- } \\
\text { Hz ratio }\end{array}$ \\
\hline 2.97 & 2.97 & 15 & 64.5 & 5.41 \\
\hline 3.96 & 3.96 & 20 & 86 & 4.95 \\
\hline 4.95 & 4.95 & 25 & 107 & 4.64 \\
\hline 5.94 & 5.94 & 30 & 133.8 & 4.46 \\
\hline 6.93 & 6.93 & 35 & 152.25 & 4.35 \\
\hline 7.92 & 7.92 & 40 & 169.6 & 4.24 \\
\hline 8.91 & 8.91 & 45 & 187.4 & 4.16 \\
\hline 9.9 & 9.9 & 50 & 205 & 4.1 \\
\hline
\end{tabular}

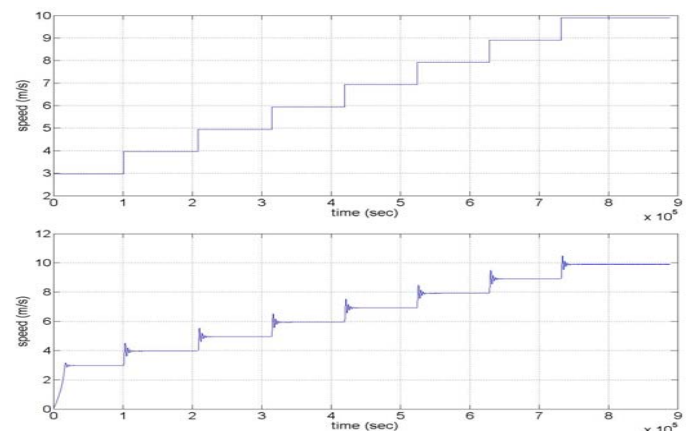

Fig. 3. Variation of reference speed and actual linear speed with respect to simulation time due to change in frequency

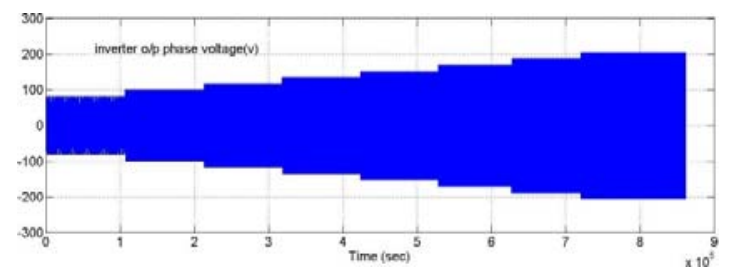

Fig. 4. Variation of inverter output phase voltage with respect to simulation time due to change in frequency

From Figures 3, 4 and Table II one can observe that actual speed is changing according to the desired reference speed. The inverter output phase voltage is also changing according to the change in frequency such that the volts/Hz ratio is almost constant with slight variation at low frequency due to the incorporation of boost voltage. Hence volts $/ \mathrm{Hz}$ control is simulated successfully.

\section{B. Case B: Effect of Boost Voltage at Low Frequency}

To show the effect of boost voltage under low frequency of $5 \mathrm{~Hz}$ the model was simulated at $20 \mathrm{~N}$ load condition applied at $15 \mathrm{sec}$. Speed and thrust performance is compared without and with boost voltage. Value of boost voltage was set at 20 volts by trial and error.

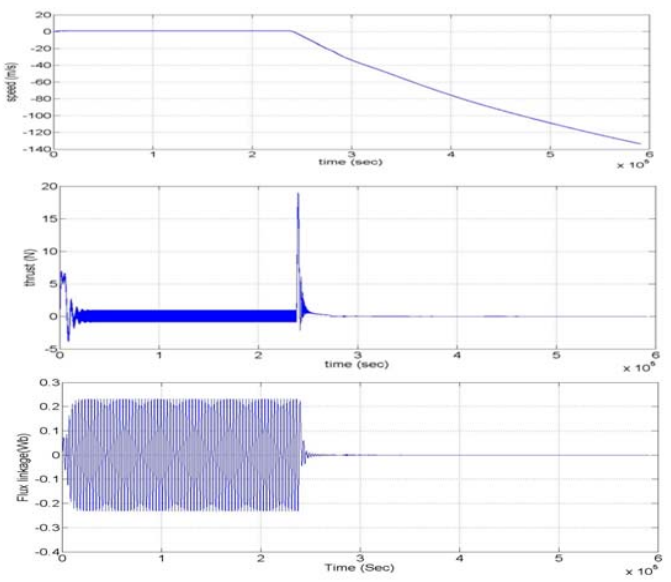

Fig. 5. Speed and thrust response at $5 \mathrm{~Hz}$ frequency and $20 \mathrm{~N}$ applied at simulation time of $15 \mathrm{sec}$ without boost voltage 

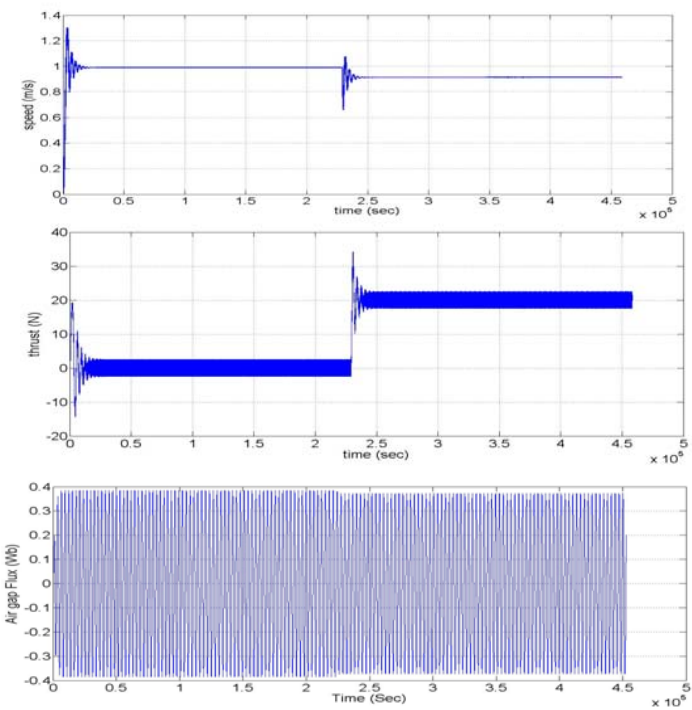

Fig. 6. Speed, thrust and air gap flux response at $5 \mathrm{~Hz}$ frequency and $20 \mathrm{~N}$ applied at $15 \mathrm{sec}$ with boost voltage of 20 volts.

Based on the simulation results, when a $20 \mathrm{~N}$ load is applied at a low frequency to the LIM based conveyor belt System the following are observed: without boost voltage control the air gap flux becomes zero and the system becomes unstable as shown in Figure 5, whereas the air gap flux does not becomes zero and the system remains stable when a boost voltage is applied as shown in the Figure 6

\section{Case C: Effect of Slip Regulation}

To demonstrate the effect of slip regulation under various loads the model has been simulated for scheduled changes in load in the sequence $\left[\begin{array}{llll}0 & 5 & 10 & 20\end{array}\right] \mathrm{N}$ at the reference speed of $2.97 \mathrm{~m} / \mathrm{sec}$ (i.e. $15 \mathrm{~Hz}$ frequency). The simulation results for cases without and with slip regulation are shown in Figures 7, 8 and Table III.

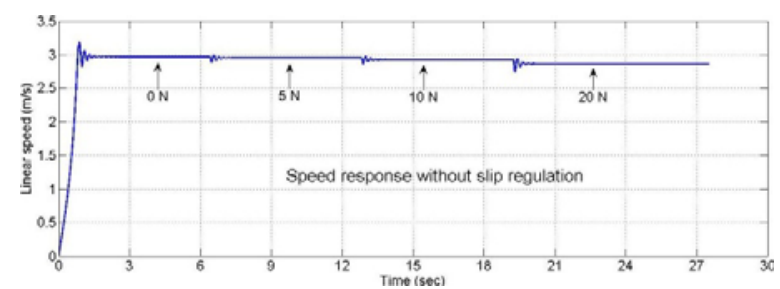

Fig. 7. Speed response without slip regulation for $15 \mathrm{~Hz}$ frequency when a $20 \mathrm{~N}$ load is applied at simulation time $\mathrm{t}=15 \mathrm{sec}$

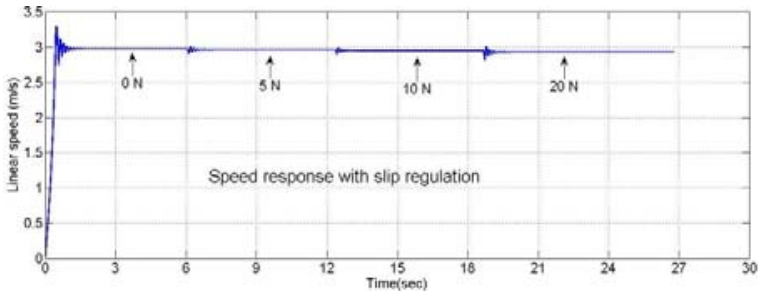

Fig. 8. Speed response with slip regulation for $15 \mathrm{~Hz}$ frequency when a 20 $\mathrm{N}$ load is applied at simulation time $\mathrm{t}=15 \mathrm{sec}$
TABLE III. SLIP-SPEED AT $2.97 \mathrm{M} / \mathrm{SEC}(15 \mathrm{~Hz}$ FREQUENCY) AT DIFFERENT LOADING CONDITIONS

\begin{tabular}{|c|c|c|}
\hline Loading condition & Without slip regulation & With slip regulation \\
\hline $0 \mathrm{~N}$ & $0.001 \mathrm{~m} / \mathrm{s}$ & $0 \mathrm{~m} / \mathrm{s}$ \\
\hline $5 \mathrm{~N}$ & $0.020 \mathrm{~m} / \mathrm{s}$ & $0.01 \mathrm{~m} / \mathrm{s}$ \\
\hline $10 \mathrm{~N}$ & $0.043 \mathrm{~m} / \mathrm{s}$ & $0.021 \mathrm{~m} / \mathrm{s}$ \\
\hline $20 \mathrm{~N}$ & $0.11 \mathrm{~m} / \mathrm{s}$ & $0.05 \mathrm{~m} / \mathrm{s}$ \\
\hline
\end{tabular}

Figures 7, 8 and Table III depict that the speed accuracy at no load (i.e at $0 \mathrm{~N}$ ) is good, both for the traditional VVVF control and the proposed closed-loop speed control method. But as the load increases slip speed for the traditional VVVF control (without slip regulation) increases whereas for the slipregulation control increase in the slip-speed is reduced. Figure 9 demonstrates the effect of slip regulation under load efficiently. Hence, it is shown that the proposed closed loop speed control with slip-regulation gives better speed accuracy.

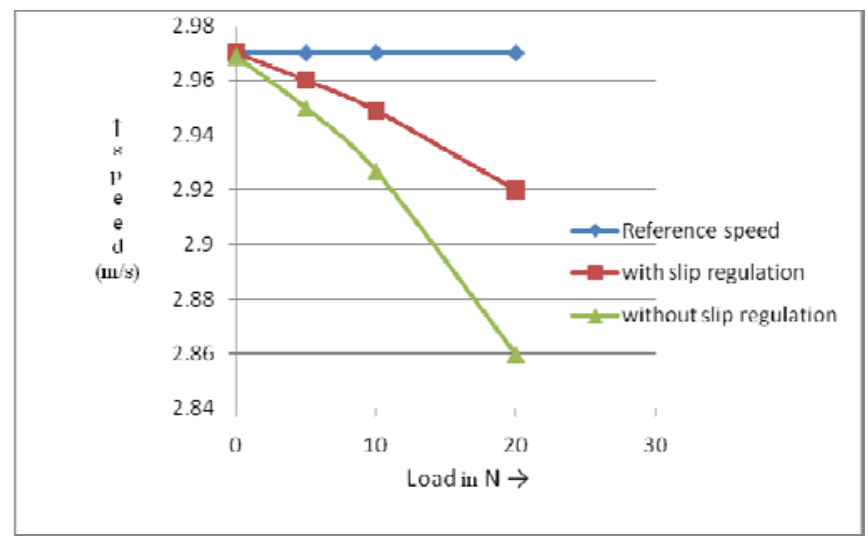

Fig. 9. Speed response at load condition

\section{Case D: Performance under Load Variation}

In this case, the reference speed is fixed to its synchronous speed of $3.96 \mathrm{~m} / \mathrm{s}$ at $20 \mathrm{~Hz}$ frequency and the load is being changed in the sequence $[0,10,-10$, and $-20 \mathrm{~N}]$. It is observed from Table IV that when the load becomes negative, LIM has entered the generating region, as the slip becomes negative. The line currents, the secondary speed, and the electromagnetic torque are shown in Figure 10.

TABLE IV. SLIP SPEED AT DIFFERENT LOADING CONDITION AT REFERENCE SPEED OF $3.96 \mathrm{M} / \mathrm{SEC}$ (I.E. $20 \mathrm{HZ}$ )

\begin{tabular}{|c|c|}
\hline Loading condition & Slip speed \\
\hline 0 & 0 \\
\hline $10 \mathrm{~N}$ & $0.22 \mathrm{~m} / \mathrm{sec}$ \\
\hline$-10 \mathrm{~N}$ & $-0.212 \mathrm{~m} / \mathrm{sec}$ \\
\hline$-20 \mathrm{~N}$ & $-.0411 \mathrm{~m} / \mathrm{sec}$ \\
\hline
\end{tabular}

\section{CONCLUSION}

The traditional Volts/Hz control scheme has the disadvantage of poor speed precision at different loads and small output thrust when working in the low frequency. To overcome these disadvantages an alternative control scheme is proposed. The incorporation of boost voltage makes the system suitable for working under low frequency conditions. Slip 
regulation maintains the speed constant at loading conditions. The results obtained through SIMULINK simulations were fair enough to validate the effect of Volts/Hz control, slip regulation and boost voltage. It should be noted that the simulation coefficient of friction was taken to be constant but in practical implementations it will change according to the speed. Also, that the mass of the belt and friction was considered under no load conditions. To validate the simulation results and incorporate the effect of mass and friction a test rig has been developed in IT BHU machines and drives lab [7]. Work is in progress and experimental results will be presented in following papers.

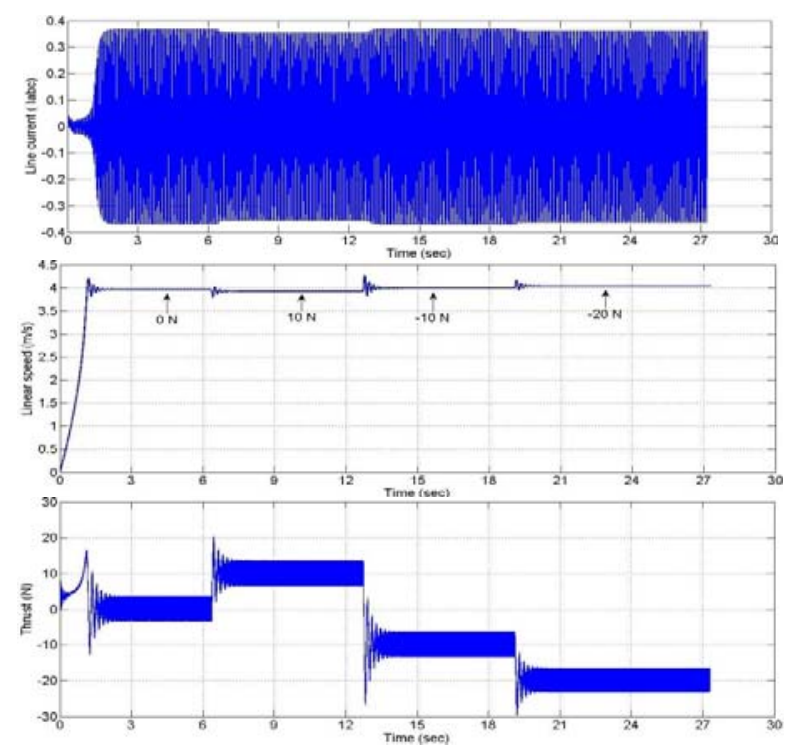

Fig. 10. Line current, linear speed and thrust response for programmed change in load.

\section{ACKNOWLEDGEMENT}

The authors acknowledge the usage of developed facility in the department of electrical engineering, Institute of Technology, Banaras Hindu University.

\section{REFERENCES}

[1] Z. Yu, D. Figoli, "AC induction motor control using constant V/Hz principle and space vector PWM technique with TMS320C240", Digital Signal Processing Solutions, Texas Instruments, 1998, [Online]. Available at: http://www.ti.com/lit/an/spra284a/spra284a.pdf

[2] B. K. Bose, Modern power electronics and AC drives, Pearson education Asia, 2002

[3] E. R. Laithwaite, S. A. Nasar, "Linear-motion electrical machines", Proceedings of the IEEE, Vol. 58, No. 4, pp. 531-542, 1970

[4] G. V. Sadler, A. W. Davey, "Applications of linear induction motors in industry", Proceedings of the Institution of Electrical Engineers, Vol. 118, No. 6, pp. 765-776, 1969

[5] S. P. Muley, M. V. Aware, "Modeling and simulation of a scalar controlled induction motor using combined inverter machine interaction in state space", 2009 Second International Conference on Information and Computing Science, pp. 3-6, United Kingdom, May 21-21, 2009

[6] A.K. Rathore, S. N. Mahendra, "Decoupled control of attraction force and propulsion force in linear induction motor drive", 2003 IEEE
International Conference on Industrial Technology, Vol. 1, pp. 524 529, 2003

[7] S. Velisetti, "Simulation and implementation of vvvf, cvvf and cfvv controls on LIM using dSpace", M.Tech. Dissertation supervised by Prof. S. N. Mahendra, Department of Electrical Engineering, Banaras Hindu University, Varanasi, India, 2011 